\title{
Reseña de La gestión integrada de playas y dunas: experiencias en Latinoamérica y Europa
}

\author{
Review of La gestión integrada de playas y dunas: \\ experiencias en Latinoamérica y Europa
}

\author{
Pablo Fraile-Jurado ${ }^{1}$
}

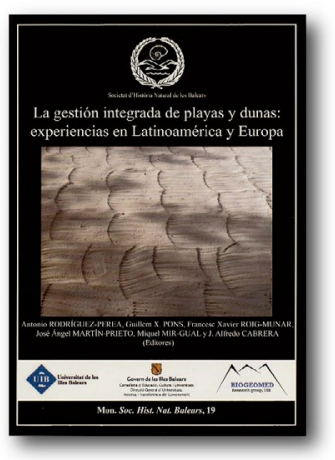

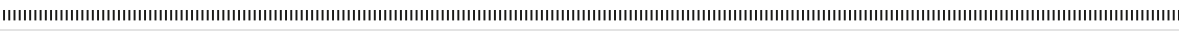

- Editores: Rodríguez-Perea, A., Pons, G.X., Roig-Munar, FX., Martín-Prieto, J.Á., Mir-Gual, M. y Cabrera, J.A.

- Título: La gestión integrada de playas y dunas: experiencias en Latinoamérica y Europa

- Año: 2012

- Ciudad: Palma de Mallorca

- Editorial: Monografies de la Societat d'Història Natural de les Balears, 19

- Páginas: 402pp.

- ISBN: 978-84-616-2240-5

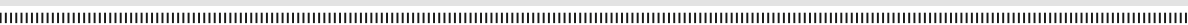

La Societat de Historia Natural de Balears presentó en el año 2012 un monográfico sobre gestión integrada de playas y dunas con una visión amplia de la gestión analizada en países de Europa e Iberoamérica, tomando como referencia diferentes casos de estudio. Este volumen establece un escenario de debate científico, técnico y profesional basado en experiencias y trabajos de investigación en el ámbito litoral de Latinoamérica y Europa, con casi 60 autores que aportan su visión y experiencia sobre el manejo integrado del litoral. Este monográfico lo componen 25 capítulos de diversa temática, desde aspectos teóricos y conceptuales a aspectos aplicados en la gestión de sistemas dunares y centrados en diferentes tipologías de playas y ambientes costeros. Se pueden consultar trabajos sobre técnicas de gestión geoambiental sostenible de sistemas playa-duna, estados de la cuestión del concepto de gestión integral de playas, tanto en Europa como en países caribeños, el comportamiento de los sistemas dunares frente a los impactos antrópicos, la clasificación de los sistemas litorales como herramienta de gestión, la evolución espacio-temporal de sistemas dunares, la aplicación legislativa, o aspectos relacionados con parámetros de comportamiento social en diferentes escenarios litorales.

El libro La gestión integrada de playas y dunas: experiencias en Latinoamérica y Europa, actualmente agotado en formato papel y disponible en formato pfd, permite una amplia visión de aspectos que actúan sobre la gestión litoral, siendo un documento de referencia en la gestión de espacios litorales en Europa y América Latina, y convirtiéndose en un amplio compendio de ejemplos a tener presentes en el estudio de los sistemas litorales arenosos. Este volumen, junto a otros relacionados con la biología, ecología, geología y geomorfología de las islas Baleares, puede ser descargado en formato pdf en el siguiente enlace: http://www.shnb.org/SHN monografies.html.

La obra abarca un amplio abanico de temas relacionados con la gestión del litoral, estando esta cuestión presente en casi todos los capítulos. Es preciso reseñar que esto constituye en sí mismo una rareza, ya que en otro tipo de obras colectivas es frecuente encontrar muchos capítulos en los que, disfrazados bajo aspectos técnicos que sirven de soporte para la toma de decisiones, se encuentran diferentes trabajos a menudo de investigación

1 Departamento de Geografía física y A.G.R. Universidad de Sevilla. pfraile@us.es 
básica. En este sentido, cabe elogiar el cuidadoso trabajo del equipo editorial, que ha conseguido que el libro mantenga una línea clara sin perderse en aspectos relacionados con el estudio del litoral pero no con la gestión. Aunque hay muchos ejemplos de ello, cabe destacar capítulos de una carga técnica indiscutible como el de El conocimiento del oleaje en España y su trascendencia para la gestión del litoral, de Torres Alfosea; o La investigación como soporte de la gestión: el ejemplo de la duna costera de Maspalomas, de Hernández-Cordero et al.; que fácilmente podrían haberse convertido en interesantes trabajos de investigación básica y que sin embargo no pierden de vista la cuestión de la gestión. No obstante, también es preciso reconocer la existencia de algunos capítulos finales en los que la carga de gestión se dispersa considerablemente, aunque en el caso de esta obra, son una minoría.

Una cuestión común a toda la obra es el proceso de uso del litoral, denominado mediante el neologismo litoralización. Se trata de un fenómeno que se da en buena parte de las costas del planeta, y que durante las últimas décadas ha conllevado una ocupación litoral masiva por parte del ser humano, rápida y acultural en la mayoría de los destinos turísticos clásicos del denominado turismo de sol y playa. Esta idea está presente en los trabajos de Flores-Mejía et al., Silva-Íñiguez et al., o Maia, entre otros de los capítulos de la obra. Como consecuencia del proceso se ha dado un proceso de cambio acelerado que frecuentemente ha producido una pérdida de identidad de estos espacios. En muchas ocasiones estas ocupaciones han dificultado y obstaculizado las estrategias y mecanismos naturales de defensa, impidiendo el buen funcionamiento de los ecosistemas. En este proceso no se concibieron las playas, las calas y las dunas como sistemas frágiles y dinámicos, susceptibles de una rápida degradación. Muchos autores coinciden en que las agresiones sobre el litoral, amparadas en factores socioeconómicos, han generado la rotura de sistemas y sus ámbitos naturales. La degradación natural del ecosistema y del paisaje en muchas ocasiones ha provocado una alteración de la dinámica litoral que no se circunscribe exclusivamente al espacio ocupado físicamente, ya que a menudo las actuaciones se promueven con la voluntad manifiesta de modificar el espacio o la creación de nuevos espacios de playas. El turismo de sol y playa ha prosperado sobre los sistemas playa-duna, y la masificación y el uso desordenado se han implantado sin otro objetivo que el incremento continuado de visitantes, tal y como se refleja en el capítulo de Pérez-López y Roig-Munar. Hacer de estos espacios un "hábitat" confortable y funcional para los visitantes ha causado problemas de conservación y de estabilidad en muchos sistemas, y en el peor de los casos su desaparición.

En muchas ocasiones los gestores responden con medidas de gestión a corto plazo, poco adecuadas para la conservación del litoral, ya que emulan medidas y técnicas asociadas a espacios urbanos, al concebir este espacio litoral, las playas, como estático. Problemas como la alteración de la vegetación y las morfologías dunares implican la alteración del conjunto del sistema dunar que se traducen en la alteración y desestabilización de perfiles de playa, el incremento del transporte eólico, la pérdida de diversidad biológica, las pérdidas de superficies y de volúmenes de playas, alteración de las fuentes de producción sedimentaria y, en el peor de los casos, la eliminación total del ecosistema o la dependencia permanente de éste de las actuaciones de "mejora" (regeneraciones y/o espigones de defensa).

No obstante, los espacios litorales son espacios públicos y de bajo coste, referentes importantes en el proceso productivo a escala local, regional y estatal, constituyendo el fundamento más sólido de la oferta turística litoral. Resulta paradójico que siendo las playas tan provechosas y complejas, tan valoradas y solicitadas, su gestión esté basada en un concepto estrictamente económico, mecánico y estático, que obvia su dinamismo y su fragilidad, entendiéndolas simplemente como espacios con una gran potencial de recaudación económica. A pesar de existir cada vez más opiniones contrarias a esta concepción estática y utilitaria aún se puede hablar de una desatención sistemática por parte de las administraciones hacia estos ecosistemas, especialmente hacia los hábitats arenosos.

Aunque cada vez son más las voces que defienden la necesidad de considerar las playas como ecosistemas a conservar y proteger, se incrementan en ellas las dotaciones de servicios, equipamientos e infraestructuras, así como gestiones de carácter rígido. Estas medidas contraproducentes para la estabilidad del sistema se justifican en dar respuesta a la voluntad manifiesta de consumir el medio litoral, ya que se entienden las playas como espacios con diversidad de ofertas de ocio, donde la satisfacción de las expectativas del visitante se convierte en sí misma en un servicio de calidad. Las autoridades prestan más atención a los visitantes, olvidando las necesidades del ecosistema que explotan, unas veces por desconocimiento del medio que gestionan y otras para ofrecer un servicio que consideran necesario, oportuno y de calidad. 
A menudo la divergencia entre la perspectiva técnica, de los usuarios o de los empresarios se ha resuelto a favor de los últimos, prevaleciendo la prestación de los servicios que satisfacen las necesidades sociales y económicas más inmediatas frente a la conservación del medio, y que en última instancia, también son necesidades sociales. Es justamente esta capacidad de satisfacer necesidades empresariales, políticas y sociales la que ha transformado los atributos del litoral en un recurso económico, convirtiendo estos espacios en algo subjetivo, relativo, funcional e incluso banal. Las playas constituyen, pues, uno de los activos geoambientales más importantes de los recursos costeros, convirtiéndose en las últimas décadas en pilares básicos de una importante economía turís- tica, de especial relevancia en países de la cuenca mediterránea, exportando el modelo a otros destinos turísticos como el Índico y el Caribe.

El libro La gestión integrada de playas y dunas: experiencias en Latinoamérica y Europa se convierte en un documento aplicado imprescindible para la formación en gestión costera, resultando de enorme trascendencia al presentar una serie de ejemplos prácticos, con lo que se convierte en un excelente complemento de los manuales tradicionales, o de planes urbanísticos y de ordenación del territorio. Al mismo tiempo, la obra es un excelente reflejo del estado actual de los estudios costeros en España y Latinoamérica en relevantes grupos de investigación. 